\title{
Acción colectiva, identidades políticas y conflicto armado: la etnización de una comunidad negra en el norte del Cauca
}

\author{
María Jimena López León* \\ (mariajalopez@gmail.com)
}

Artículo de investigación recibido el 29/11/2014 y aprobado el 19/12/2014

Cómo citar este artículo:

LÓPEZ LEÓN, María Jimena (2014). “Acción colectiva, identidades políticas y conflicto armado: la etnización de una comunidad negra en el norte del Cauca". En: Trans-pasando Fronteras, núm. 6, pp. 55-82. Cali, Colombia: Centro de Estudios Interdisciplinarios, Jurídicos, Sociales y Humanistas (CIES), Facultad de Derecho y Ciencias sociales, Universidad Icesi.

\section{Resumen}

El presente artículo tiene como objetivo analizar el proceso de producción de acción colectiva no violenta en una comunidad afrocolombiana nortecaucana en respuesta a las conflictividades sociales, políticas y ambientales que han puesto en riesgo su permanencia en el territorio. Se presentan elementos de análisis del trabajo etnográfico realizado por la autora durante 2012 y 2013 en el municipio de Santander de Quilichao. El desarrollo teórico del artículo toma el concepto propuesto por Elisabeth Wood sobre los procesos sociales de la guerra civil (2010) para establecer correspondencias entre las dinámicas sociales generadas por el conflicto armado -agudizado desde el 2008 en la región- y los procesos de acción colectiva y agenciación de la identidad de una población afrocolombiana. Algunos

* Antropóloga de la Universidad Nacional de Colombia. Mágister en Estudios políticos y Relaciones Internacionales de la misma universidad. 
de estos conflictos son las tensiones territoriales entre distintos actores sociales por los procesos de legalización y expansión de territorios étnicos, la explotación minera, el proceso de Consolidación Territorial; así como el fortalecimiento de las alianzas organizativas interétnicas, y del proceso organizativo de comunidades negras de la zona. Bajo estas condiciones, las narrativas sobre la "ancestralidad", el "ser negro" y la "autonomía", se han convertido en ejes orientadores de la acción colectiva que legitima la presencia territorial de la población de estudio, así como su exigencia en el acceso a derechos como la titulación colectiva y la consulta previa.

\section{Palabras clave}

Acción colectiva, frontera étnica, procesos sociales de la guerra civil, Norte del Cauca, afrocolombianos

\section{Introducción}

El 16 de septiembre del año 2014 las comunidades del Consejo Comunitario Zanjón de Garrapatero y del Resguardo Nasa de Guadualito se reunieron en Asamblea Interétnica en la jurisdicción territorial de esta última. El propósito de esta reunión fuegenerar un acuerdo y una serie de acciones conjuntas para frenar el avance de la minería de aluvión no legal en sus territorios. Entre las medidas establecidas se incluía la confiscación de maquinaria y la expulsión de personas destinadas a la explotación de oro sin contar con la consulta previa, libre e informada a las autoridades tradicionales respectivas (Asamblea interétnica, 2014). Casi un mes después de esta declaratoria, el 29 de octubre llegaría un panfleto de la banda criminal Los Rastrojos amenazando de muerte a diez líderes comunitarios que participaron de esta Asamblea y de las tantas otras acciones contra la minería.

Ambos hechos son el punto de llegada de la resistencia de una comunidad negra ubicada en la zona rural de Santander de Quilichao, que desde el año 2008 se constituyó como Consejo Comunitario (C.C.)de comunidades negras en respuesta a una serie de conflictividades -latentes y agudizadas- que afectarían su permanencia en el territorio. La primera de estas conflictividades sería el otorgamiento de un título minero a la transnacional canadiense Anglo Gold Ahsanti en su territorio sin que se hubiera realizado la consulta previa, libre e informada. La segunda, ha sido el emblemático conflicto territorial por la Hacienda San Rafael protagonizado con una comunidad indígena del resguardo de Toribío -también de la etnia Nasa- por la titulación que hizo el Estado de esta hacienda siendo territorio ancestral de la comunidad negra mencionada. El tercer conflicto el de la minería ilegal tendría su cara más aguda en el año 2009. 
Cada una de estas conflictividades, vividas por el C.C. de Zanjón de Garrapatero a partir del año 2008, ha incentivado la resignificación de la identidad colectiva del proceso organizativo de esta comunidad como étnica y su politización en el reconocimiento de los derechos étnico-territoriales establecidos en la Ley 70 de comunidades negras. De igual manera, las movilizaciones y acciones reivindicativas generadas por el consejo comunitario han ido transformando el contexto que ha motivado su producción, logrando convertir algunos de estos conflictos en oportunidades para su proyecto político-cultural como autoridad étnicoterritorial, mientras que otros se han agudizado de forma tal que han puesto en riesgo la vida de las y los líderes del Consejo Comunitario. Las preguntas que espero desarrollar a lo largo de las siguientes páginas son dos: cómo estas conflictividades han incidido en la producción de acción colectiva de la comunidad estudiada; y qué papel ha jugado la identidad colectiva del "ser afro", en el accionar conjunto de la comunidad estudiada, específicamente en la interpretación y transformación de los escenarios de conflicto.

Para ello, en este análisis presentaré los resultados de la etnografía que realicé al proceso organizativo del Consejo Comunitario de Zanjón de Garrapatero en el 2012 y el 2013 como parte de mi proyecto de tesis de maestría. La temporalidad del estudio de caso va desde el año de su creación en el 2008 hasta el 2013, año en el que finalizó el trabajo de campo. La investigación tuvo como propósito analítico la comprensión de la relación entre un contexto de conflictividades armadas o de procesos sociales derivadas de la misma y la producción de acción colectiva no violenta. Parte de la respuesta que he formulado a esta pregunta, y que será presentada en las páginas siguientes, está relacionada con la posición que toma la construcción de una narrativa propia que le da sentido a la construcción de "un nosotros" o una idea de colectividad, así como a la manera en que es leído o interpretado el contexto de conflicto en el que se produce la acción. Con esta decisión analítica hago explícito al lector un distanciamiento de este artículo frente a la perspectiva racionalista en el estudio de la movilización social, en la cual toda la lógica de la acción colectiva se reduce al cálculo que hace el individuo entre el costo de producir la acción y el beneficio de la misma. En ella el actor colectivo se entiende como la congruencia de los intereses de los actores individuales quienes buscan su inmersión dentro de la economía del mercado o simplemente su inclusión y reposicionamiento dentro de la lógica del Estado (Cohen, 1995: 27-28). 
Sin embargo, como será visto en este estudio de caso, no toda la movilización social obedece de manera exclusiva a esta racionalidad estratégica. La acción colectiva producida en situaciones de riesgo es una prueba de ello.

Habiendo dicho esto último, explicito también que sigo la definición de Alberto Melucci sobre la acción colectiva como "una orientación intencional", o una "inversión organizada" encaminada a darle sentido al "estar juntos" (1994: 157). La acción colectiva al ser considerada como unidad de análisis de los movimientos sociales permite centrar la atención en dinámicas particulares de éste fenómeno social, es decir, identificar cómo se colectiviza un interés y cómo se movilizan estrategias y recursos para alcanzarlo. Para la situación colombiana enfocarse en esta unidad permite orientar el análisis hacia la evidencia empírica y no caer en los presupuestos teóricos que limitan el estudio de la movilización a contabilizar la ausencia o presencia de movimientos sociales, evitando responder a cómo se construyen y sostienen estas movilizaciones en la diversidad de los contextos que el país ofrece.

De esta manera presento mi segundo distanciamiento de la literatura académica nacional de orientación racionalista, desde la cual algunos autores han buscado medir la existencia o no de movimientos sociales partiendo de marcos conceptuales y no de las características reales de la movilización en el país. De esta manera quedan sin ser analizadas las condiciones particulares de estas movilizaciones así como la dinámica de las alianzas, entrecruzamientos y solidaridades entre la sociedad civil colombiana.

El artículo está organizado de la siguiente manera: en la segunda parte se abordan los elementos teóricos que soportan las ideas y distanciamientos aquí presentados, continuaré presentando las características del contexto sociopolítico en el que se desarrolla el estudio de caso, luego seguiré con la presentación de los aspectos más relevantes del proceso organizativo estudiado, para avanzar en la quinta parte, sobre las relaciones entre la acción colectiva producida y el contexto que la motiva y en el que se desarrolla. Se finalizará con unas conclusiones.

\section{Marco teórico}

Son dos las líneas teóricas que alimentan la interpretación del estudio de caso: la acción colectiva comprendida desde la perspectiva constructivista e identitaria y la comprensión del contexto en el que se produce la acción, como amenaza u oportunidad. 
En primer lugar, opto aquí por una aproximación constructivista de la acción colectiva, que entiendo -siguiendo a Alberto Melucci- como un "proceso interactivo, comunicativo y negociado" (Melucci; 1994). Esto significa que la acción es el producto de la interacción que se genera entre los actores que participan de la confrontación, así como de la definición que estos hacen del campo en el que tiene lugar su acción y de sí mismos (Melucci, 2002). Allí, la identidad no es una construcción preexistente sino que se convierte en el producto de una construcción intencional, de una "inversión organizada" de recursos simbólicos y materiales que responde a la pregunta de cómo el individuo se define en relación con el ambiente de conflicto en el que está inmerso (Melucci, 1994; 2002). Esta comprensión de la acción colectiva como el producto de una interacción social implica al menos tres cosas que serán centrales en el estudio de caso que propongo.

Primero, la comprensión de la acción se orienta a la comprensión de la construcción de sentido, esto implica comprender la manera en que los actores sociales se definen a sí mismos, como al campo en el que tiene lugar su acción (Melucci, 2002). Esta premisa tomaría sentido si entendemos que el campo en el que se produce la acción define las estrategias que los actores utilizan para responder al conflicto.

Segundo, sitúa la acción en el plano de las relaciones sociales y de lo cotidianidad. Esto implica orientar la mirada hacia las relaciones cotidianas en una organización y comprender la manera en que los sentidos colectivizados adquieren matices, nuevos significados o incluso tensiones al interior de la organización.

Tercero, descentra la comprensión de la acción colectiva en la relación sociedad civil-Estado y orienta la mirada hacia lo que sucede al interior de las poblaciones y comunidades que participan de la acción, es decir en cómo son producidas las alianzas estratégicas y cómo se movilizan los recursos en ella (Melucci, 2002).

Ahora, ¿cómo se produce la identidad colectiva y cómo este sentido de colectividad puede verse afectado por el contexto en que se inspira y se produce la acción colectiva?. Para las comunidades norte caucanas la identidad étnica se ha convertido en un eje central en el discurso. La identidad étnica como un proceso de producción de diferencia cultural y política, se encuentra frecuentemente asociada a procesos de reivindicación y restitución de derechos, de tal forma que el reconocimiento étnico de una población implica su reconocimiento propio como comunidad política. Esta "organización de la diferencia en una sociedad" como ha sido 
definido por Büschges y Pfaff-Czarnecka (2003), ha conducido al fenómeno de "etnización de lo político" que es descrito por los autores como la producción de discursos que toman lo étnico y lo racial como lugares de enunciación desde los cuales se busca incidir en la toma de decisiones políticas y de política pública (Büschges y Pfaff-Czarnecka, 2003).

En el caso de la comunidad Zanjón de Garrapatero el contexto de conflictividad interétnica y de reconfiguración del conflicto armado en la zona, ha incidido en que la comunidad haya definido la etnicidad como el horizonte discursivo de su movilización, organizándose como consejo comunitario. Asimismo, las dinámicas que ha asumido el contexto y las alianzas establecidas en el curso del mismo, le han motivado a que defina una acción colectiva de tipo contestaria y con elementos de interculturalidad.

Según la aproximación etnográfica propuesta para el estudio del caso, la pregunta por la identidad debe ser evaluada desde la comprensión de los relatos que los miembros de la comunidad, sus líderes y las personas del común, hacen sobre su propio proceso, sobre los conflictos que los asedian y sobre las acciones y principios que las sostienen. Estas narrativas o relatos de la movilización social permiten intervenir las narrativas del sentido común, transformar o inclusive generar cuestionamientos a las mismas a partir de sus narrativas propias (Polleta y Chen, 2012). Este proceso se da en una doble vía: construyendo sentido común y generando un desafío al mismo (Polleta y Chen, 2012). Desde allí puede analizarse la manera en que es estructurado y organizado el sentido de colectividad del movimiento o del proceso organizativo, la interpretación que este tiene sobre el contexto en el que se produce la acción y sobre los actores que participan de esta, y cómo logra establecer continuidades o discontinuidades en las temporalidades del movimiento o incluso entre las narrativas individuales y colectivas. De igual manera permite evidenciar matices de diferenciación, relaciones de poder y autoridad al interior del movimiento e incluso los recursos simbólicos utilizados para ello.

Habiendo definido cómo entiendo aquí la acción colectiva y su relación con la identidad colectiva, a continuación explicaré cómo entiendo la relación entre acción colectiva, el conflicto y el contexto.

Charles Tilly, Sydney Tarrow y Doug McAdam plantean cómo los cambios en la estructura formal del sistema político inciden en la dinámica de los movimientos sociales generando posibilidades para la acción colectiva o formas específicas de 
acción (MacAdam, MacCarthy, Zald, 1999). Este enfoque teórico conocido como el proceso político, subraya la importancia de los conflictos y las coyunturas políticas en la movilización social, especialmente en la dinámica generada por las élites y las instituciones estatales y su incidencia en la producción de la acción colectiva (McAdam, McCarthy y Zald, 1999).

Uno de los aspectos significativos de este enfoque teórico, que aquí retomo, ha sido la comprensión de los movimientos sociales a partir de la interacción estratégica entre el actor que se moviliza, el contexto sociopolítico en el que se desenvuelve la acción, el actor opuesto o contra el que está dirigida, y, agregaría, con los demás actores de la sociedad civil que constituyen un capital social y estratégico significativo. Siguiendo este enfoque, si bien Sydney Tarrow ya mencionaba que la apertura del sistema político podían constituirse en oportunidades para la movilización social (Tarrow, 1997), para Goldstone y Tilly un contexto de amenaza y represión pueden generar condiciones de oportunidad también (Goldstone y Tilly, 2001).

No obstante en un contexto como el norte caucano donde si bien ciertas condiciones restrictivas impuestas por la confrontación armada son convertidas en oportunidades de movilización por las organizaciones sociales, el tipo de acción producida no siempre generará una apertura del sistema político sino que, es posible, genere mayor restricción. Así lo abordan Ricardo Peñaranda y otros autores en su libro Contra viento y marea. Allí los autores mencionan que un sistema político restringido podrá generar una condición de mayor represión de la acción colectiva, pero a su vez, podrá facilita la construcción de nuevas alianzas con otros grupos de la sociedad civil que garanticen el sostenimiento de la acción colectiva en el tiempo (Restrepo, García, y Bautista, 2010).

De esta manera, y aquí propongo el segundo punto, las características del conflicto en el que se produce la movilización inciden en la manera en que los actores que se movilizan configuran su identidad colectiva y el horizonte discursivo desde el cual desarrollarán la estrategia colectiva. No obstante, el contexto no incide de manera unilateral, sino que los actores que se movilizan están en la capacidad de incidir en él. Es a partir de la definición que la comunidad haga del contexto y de sus conflictos, en términos de amenaza u oportunidad, lo que determina su respuesta organizativa frente al mismo. Esto implica tres premisas. 
Primero, la existencia de un contexto de violencia o de conflicto puede incidir en la reconfiguración, reafirmación o transformación de la identidad colectiva de un grupo social, como parte de un proceso organizativo de respuesta a la condición de dominación impuesta por el actor armado. Segundo, la interpretación que estos mismos actores hacen del conflicto que los afecta determina a su vez el tipo de acción colectiva y la respuesta organizativa que ellos producen (enmancipatoria, contestataria, de resistencia a la guerra). Tercero, un proceso de movilización supone un proceso de interacción que involucra tanto los hechos generadores del conflicto, los actores que generan el conflicto, y otros actores que como la sociedad civil, pueden ser estratégicos para el movimiento social o para la acción colectiva. En este proceso de interacción, no obstante, la incidencia o afectación se produce tanto del conflicto hacia al actor que se moviliza, como de su oponente hacia este, y viceversa.

En síntesis, la pregunta por la identidad es importante para el estudio de la movilización producida en contextos de violencia o de guerra, se trate o no de comunidades étnicas. La comprensión tanto de las formas de solidaridad que tienen lugar en una movimiento o un accionar colectivo, así como de la construcción de una historia y objetivos comunes, son procesos que hacen parte de la configuración de una identidad colectiva sedimentada, y que, en estos casos, garantizan la sostenibilidad del movimiento así como la vida de quienes forman parte de éste cuando la movilización pone en riesgo la integridad de sus protagonistas. El giro por la identidad vuelve posible la existencia de estas preguntas, pero las respuestas posibles surgen de un análisis que involucre otras variables relevantes como lo es el lugar y el contexto, y la interacción entre estos y los actores que producen la acción. Veamos por qué.

\section{El contexto}

El municipio de Santander de Quilichao, lugar en el que se localiza el Consejo Comunitario Zanjón de Garrapatero, y denominado la segunda capital del Cauca, es un centro de intermediación para la distribución de bienes y servicios para el norte del departamento. Esta condición que se debe a su ubicación geográfica, permitiendo conectar el nororiente y el sur del departamento con la ciudad de Cali, y a una buena accesibilidad, han hecho de esta ciudad un foco de disputas y de acciones de confrontación entre actores armados. De allí que sea el segundo municipio con mayores homicidios durante el período 1990- 
2003, el primero en masacres con ocho, el segundo en secuestros y el segundo con mayor conflictividad en todo el departamento (Verdadabierta 2014). Al respecto dice uno de los líderes entrevistados de la Asociación de Cabildos Indígenas del Norte del Cauca, ACIN:

\begin{abstract}
"[...] Aqui en Santander pasa algo muy complejo. Es que primero es una zona de confluencia del norte del cauca, del comercio y de organizaciones, y segundo que es una zona altamente afectada por el tráfico y consumo de drogas, también por la presencia de grupos paramilitares. Lo más complejo es que todo eso se mantiene en un bajo perfil, aqui se pueden contar homicidios diariamente, y casi no se sabe. Por robos por pandillas, por controlar el tráfico de drogas, pero casi no se hace tanto escándalo por estos homicidios, pasa desapercibido.
\end{abstract} Se visibiliza por la presencia de las organizaciones sociales. " (Capaz, 2012)

Si bien el casco urbano de Santander es un centro de comercio, la zona rural está dedicada a la producción de alimentos, el $52 \%$ del suelo está destinado al cultivo de caña y el 39\% restante se dedica a la producción de alimentos (Secretaria Departamental de Salud, 2012), a diferencia de otros municipios, allí se mantiene aún la tradición productiva familiar. El $27.703 \%$ de la población es afro, $16.60 \%$ indígenas y 33.090\% mestizos (Secretaria Departamental de Salud 2012, 16) De ellos, un $42.6 \%$ residente en la zona urbana y el $57.4 \%$ en la rural (Secretaria Departamental de Salud 2012). Las comunidades étnicas del municipio están organizadas en 4 resguardos: Munchique-Los Tigres, Canoas, la Concepción y Guadualito, y 5 cabildos; y en 4 consejos comunitarios de comunidades negras: Consejo Comunitario Aires de Garrapatero ubicado en la vereda San Antonio, el Consejo comunitario Zanjón de Garrapatero ubicado en siete veredas (El Palmar; Mazamorrero, Bajo San Francisco, Santa Lucía, La Toma y Ardovelas) y el Consejo Comunitario Cuenca del Río Páez-Quinamayó, el cual abarca trece veredas y es el único que cuenta con reconocimiento legal ante el Ministerio del Interior.

Santander de Quilichao al igual que el resto del norte del departamento ha sido escenario, en los últimos años, de lo que podría ser visto como una reconfiguración del conflicto armado. Para Teófilo Vásquez, Andrés Vargas, y Jorge Restrepo lo que ha sucedido desde el año 2008 en esta subregión del suroccidente es que se están generando nuevos contextos que han afectado la manera en que los actores armados 
desarrollan estrategias para insertarse en las economías locales y por tanto en las dinámicas territoriales (Vásquez, Vargas y Restrepo 2011). Estos nuevos contextos los he organizado en las siguientes cuatro categorías.

Primero, la agudización de la violación a los derechos humanos y al derecho internacional humanitario. Este se explica por el regreso de las FARC a la guerra de guerrillas así como por una agudización de la disputa territorial entre actores armados por el control de los modos de producción y distribución de la droga. De otro lado las acciones de la fuerza pública también se han incrementado como parte de la política del Plan Nacional de Consolidación y Reconstrucción Territorial, heredero del Plan Colombia ${ }^{1}$.

Segundo, la revitalización de las redes de movilización social contra la guerra y por la autonomía territorial en los últimos años en el norte del Cauca. Gran parte de estas movilizaciones han tenido como propósito reivindicaciones por la titulación, saneamiento, ampliación y legalización de resguardos, consejos comunitarios y para la creación de zonas de reserva campesina. Esto último, ha generado en casos puntuales, tensiones entre procesos organizativos locales por la titulación de algunos predios, ante el espejismo de la "escasez de la tierra", tal es el caso de la Hacienda San Rafael. A su vez, este fortalecimiento de las alianzas entre organizaciones, comunidades y procesos de la sociedad civil, ha sido el producto de una amplia trayectoria organizativa en el norte del Cauca que permite considerar la existencia de un sentimiento de comunidad entre las poblaciones civiles norte caucanas.

1 El Plan Nacional de Consolidación nació en el gobierno de Álvaro Uribe y tuvo como prueba piloto, desde el año 2007, a la región de la Macarena. Se planteó en ese momento como una "estrategia de recuperación social e institucional del territorio" (Consolidación). En el 2010 fue retomado por el presidente Juan Manuel Santos como parte del Plan Nacional de Desarrollo 2010-2014, bajo el nombre de Política Nacional de Consolidación y Reconstrucción Territorial (PNCRT). En el 2011, por medio del Decreto Ley 4161 del 3 de noviembre se creó la Unidad Administrativa Especial para la Consolidación Territorial (UACT), que fue integrada al Departamento Administrativo para la Prosperidad Social, DPS (antes Acción Social).

La crítica que se ha hecho al Plan Nacional de Consolidación desde sus inicios ha sido el protagonismo que ha tomado el enfoque militar del proceso dejando de lado el fortalecimiento del poder civil en lo local. El informe de WOLA sobre el programa la ausencia de la población civil ha podido evidenciarse en los siguientes aspectos: la ausencia de jueces y procedimientos de justicia ante el aumento de las violaciones a los derechos humanos y la corrupción; la ausencia de servicios de apoyo económico y de seguridad alimentaria, como proyectos de reemplazo a la producción de cultivos ilícitos; la ausencia de programas de recuperación del campo y de la productividad legal y la ausencia de proyectos de infraestructuras y de mejoramiento de vías (Isacson, 2012). 
Tercero, la dinámica de los conflictos por la tierra en Santander de Quilichao que tiene unos antecedentes históricos amplios que se remontan a la historia de las haciendas azucareras y a su paso hacia los ingenios, ha ido mutando por la llegada de la minería ilegal y de sus consecuentes conflictos socioambientales. Los empresarios mineros se han instalado en los territorios de las comunidades rurales a través de prácticas como el arrendamiento por porcentaje de oro lavado, el soborno a miembros de la comunidad y la contratación de una seguridad privada armada que por lo general está respaldada por algún BACRIM. Los entables mineros se instalan en el predio arrendado y se van expandiendo en la medida en que logran seducir a nuevos arrendatarios. Con el entable llegan no solo las armas, sino barequeros de otras partes del país incentivados por el rumor del oro, llega -o se agudiza- la prostitución y la trata de blancas e incluso el microtráfico de drogas. Estas problemáticas sumadas a los impactos ambientales, sociales y culturales que generan la manipulación, privatización y contaminación de las fuentes de agua, están incidiendo en nuevas prácticas de despojo, en la desarticulación comunitaria y en la disminución de la producción agrícola.

Cuarto, la dinámica del conflicto que se ha vivido en el norte del Cauca ha generado unas transformaciones específicas en las relaciones y dinámicas sociales de la comunidad norte caucana, Elisabeth Wood ha denominado estos cambios como los procesos sociales de la guerra civil (Wood 2010). El conflicto que se vive en Santander como en el norte del departamento del Cauca se caracteriza por la superposición de un conflicto histórico innegable entre guerrillas, grupos paramilitares y fuerzas armadas del Estado, y por los procesos sociales de la guerra civil que ha dejado esa historia de la confrontación y del involucramiento de la población civil como objetivo de guerra. Estos cambios son entendidos aquí de la manera en que Elisabeth Wood los conceptualiza: a) militarización de la vida civil, b) transformación de identidades y c) fragmentación de la economía política, entre otros, cada uno de estos procesos han sido el producto de los impactos que ha generado una política de transición hacia un postconflicto en la zona: que implica la recuperación del territorio y de la fuerza de parte del Estado y que se ha convertido en un condicionante para la generación de nuevos conflictos.

La militarización del gobierno local es entendida por Wood como la suplantación de formas de gobierno locales por otras con influencia de los actores armados. Este proceso ha tenido lugar en el norte del Cauca partir de dos variantes: una ha sido la intervención 
de los actores armados ilegales en la cooptación de los gobiernos locales a partir del poder armado, y otra, la recuperación del control estatal en los territorios a partir del aumento del pie de fuerza. El caso de estudio se encuentra en un período de transición hacia el segundo proceso.

Las conflictividades interétnicas que han tenido lugar en el norte del Cauca han sido causadas por la concentración de la tierra. Ésta ha generado escasez de tierras para los territorios colectivos y los minifundios de los campesinos, lo que ha conducido, a su vez, a que las fincas disponibles para la expansión y el saneamiento de resguardos, la legalización de territorios colectivos de comunidades negras y la titulación a familias de campesinos sean peleadas por estos actores al mismo tiempo. Esta condición, junto con un proceso de sedimentación de identidades étnicas que se ha desarrollado como estrategia de reconocimiento de derechos territoriales, ha llevado a que haya un ambiente de competencia y rivalidad entre algunas organizaciones y comunidades del norte del Cauca.

La relación entre guerra y despojo ha facilitado el tránsito de las economías campesinas y tradicionales de minifundio hacia las economías ilegales y las economías extractivistas. En la parte plana del norte del Cauca, el fenómeno ha sido la inserción de la minería, tanto legal como no legal. Ambas han llegado a los territorios con generando impactos económicos similares a los de la economía de la coca, sólo que el nuevo referente de cambio es el oro. En cuanto a las formas de trabajo, dado que la actividad de barequeo, como el de raspar coca, dependen de los ciclos de producción del entable minero y del cultivo, luego de que éste termina la mano de obra disponible, que bien o ha perdido su tierra o la ha dejado de cultivar, migra en la búsqueda de un nuevo entable o de otro cultivo ilícito. El desprendimiento social que han causado ambas economías, han generado una condición mucho más difícil para los procesos organizativos de las mismas comunidades: han agudizado las divisiones internas. Si una comunidad decide hacerle frente a la minería no cuenta con el respaldo de toda la población, pues la mitad de ella resulta cediendo sus parcelas para la explotación mediante el arrendamiento y el pago por porcentaje, otra resulta trabajando como barequeros en las minas. Tal es el caso de Zanjón de Garrapatero, donde si bien hay veredas, familias y líderes en contra, otra veredas, otras familias y otros líderes están de acuerdo con ella, pero la amenaza de la minería transnacional sí parece estar uniendo a las comunidades, y allí los oponentes están claramente definidos: el Estado y las corporaciones. 
Veamos cómo estos cambios en la configuración del conflicto armado en el norte del Cauca han impactado a los actores sociales de esta subregión, particularmente de aquella que pertenece al Consejo Comunitario Zanjón de Garrapatero.

\section{El actor: Consejo Comunitario Zanjón de Garrapatero}

El Consejo Comunitario Zanjón de Garrapatero tiene una jurisdicción territorial que incluye seis veredas del municipio de Santander de Quilichao: La Toma, Ardovelas, Santa Lucía, El Palmar, Bajo San Francisco y Mazamorrero. Su población es totalmente rural y en su mayoría se dedican a la producción agrícola de panela, piña, mango, chontaduro.

$\mathrm{Su}$ trayectoria organizativa se remite a la década del 80 a los comités veredales con los que se buscó promover acciones que mejoraran la calidad de vida de la comunidad. Es así como se promueve la construcción del acueducto comunitario, la implementación de una trocha que facilitara la movilidad de las comunidades de la zona, así como la comercialización de sus productos. No obstante, a partir de la década del 2000 suceden dos cosas que cambiarían el curso de su proceso organizativo: primero, a partir de la Ley 743 de 2002 cada vereda comenzó a organizarse bajo la figura de la Junta de Acción Comunal, y segundo, en común acuerdo con las comunidades afro, campesinas e indígenas vecinas se constituye un Comité Zonal con el que se buscó implementar proyectos que contribuyeran al desarrollo en la zona. Es a partir de la creación de este último que se comienza a trabajar en la constitución de un comité pro Consejo Comunitario.

Aunque en años anteriores la comunidad ya había escuchado sobre la Ley $70,{ }^{2}$ no fue sino hasta el 2008 que se organizó bajo esta figura con el nombre de Consejo Comunitario Zanjón de Garrapatero. Sucedieron dos cosas que incidieron en dicha decisión. En el 2008 la USAID abrió una convocatoria para el fortalecimiento de proyectos productivos para comunidades étnicas que estuvieran organizadas bajo cabildos y consejos comunitarios en el norte del Cauca, oportunidad que incentivo a que varias comunidades de la zona se constituyeran como consejos comunitarios. De otro lado, en el mismo año un conflicto territorial comenzó a desarrollarse en una finca ubicada en el territorio de la comunidad de Garrapatero.

2 Ley colombiana que ampara los derechos étnico-territoriales de comunidades negras, afrocolombianas, palenqueras y raizales. PCN, Proceso de Comunidades Negras. ACONC, Asociación de Consejos Comunitarios del Norte del Cauca. Para mayor información ver el estudio de Alejandra Erazo Gómez (2012) 
La finca, conocida como San Rafael, fue titulada el 28 de diciembre del 2008 por el Ministerio del Interior a la comunidad indígena Nasa del Resguardo de Toribío. La titulación se hizo en respuesta a los Acuerdos del Nilo, establecidos entre ambas partes en reparación a la masacre del mismo nombre, que fue cometida en 1991 contra la comunidad indígena en el municipio de Caloto (norte del departamento del Cauca).

Si bien el dueño anterior de la finca era un mestizo, San Rafael había sido por muchos años el sitio de trabajo y de paso de la comunidad afrocolombiana de Zanjón de Garrapatero. De allí se surtían de maderas, de pasto para sus animales y del jornal cortando la caña que había sembrado su dueño. Una vez la finca fue titulada a la comunidad indígena, ésta se instaló allí generando sorpresa y molestia entre la población afrocolombiana que habitaba en sus alrededores al no haber sido notificada ni consultada por el estado ni por los indígenas. El desconocimiento de los indígenas de la cercanía de la comunidad afro con la finca, así como los cambios en la cotidianidad que provocaron los indígenas de Toribío que al igual que los afros sienten su derecho legítimo de permanecer allí, significó el inicio de una serie de tensiones entre ambas comunidades que terminaría con varios enfrentamientos físicos, y finalmente con la muerte de dos indígenas y de un mestizo.

El conflicto interétnico funcionó como contexto detonante para que la comunidad afrocolombiana organizara una respuesta centrada en la reivindicación de sus derechos territoriales como comunidad étnica ante el Estado, bajo la figura de la titulación colectiva de la finca en disputa. Mientras que la financiación de la USAID se convirtió en una oportunidad política que le permitió al Consejo Comunitario fortalecerse como una autoridad legítima en la mediación del conflicto de San Rafael. Asimismo, a partir del conflicto de San Rafael y de la constitución del Consejo Comunitario, el Comité Zonal dejó de funcionar y las relaciones entre las poblaciones indígenas vecinas y afrocolombianas comenzaron de deteriorarse.

El proceso de San Rafael, no obstante, se dilató hasta que a mediados de 2013 cuando se realizó la consulta previa al Cabildo de Toribío para que autorizara la venta de San Rafael a los afros, y la compra de otro predio en iguales condiciones. Sin embargo, de mediados de 2013 hasta el mes de octubre ambas comunidades se enfrentaron a una nueva espera, por lo que la comunidad de Zanjón de Garrapatero junto con otras comunidades afrocolombianas 
del Cauca se movilizaron hacia Popayán el 31 de octubre de 2013 e hicieron una toma pacífica de las oficinas del Incoder. A partir de la mesa de diálogo instalada después de esta movilización, el Incoder compró la finca Barrancón y en diciembre de 2013 se la entregó al Cabildo de Toribío (Verdadabierta 2014). Finalmente el 28 de febrero el Incoder hizo también la entrega de San Rafael al Consejo Comunitario Zanjón de Garrapatero, no obstante, este último quedó en espera de la finca fuera titulada colectivamente.

Sin embargo, en los años siguientes se producirían nuevos hechos que marcarían un segundo momento en el proceso organizativo de la comunidad caracterizado por una apertura en la construcción de alianzas estratégicas con las comunidades indígenas y afrocolombianas de la zona en una apuesta por la defensa del territorio y por la construcción de una propuesta de autonomía territorial interétnica. Los tres hechos significativos son: la llegada de la minería ilegal, la concesión de un título minero a una transnacional y la llegada del llamado Plan Nacional de Consolidación Territorial.

En el 2009 se instaló el primer entable minero en una de las veredas del ya constituido Consejo Comunitario. Los mineros provenientes del departamento de Nariño comenzaron la explotación de oro bajo la forma de arrendamiento de la tierra en los predios de personas que no vivían allí pero que tenían predios disponibles. En poco tiempo lograron convencer a una parte significativa de la comunidad veredal. No sólo se generaron evidentes impactos ambientales en como el cambio del curso del río Quinamayó, eje de la vida social y cultural de varias comunidades, sino fragmentaciones en el proceso social y político que lideraba la JAC y el Consejo Comunitario.

Ante la expansión del problema a las otras veredas y el apoyo que manifestaba abiertamente la comunidad a los entables mineros de los cuales se beneficiaban con el bareque, los líderes del Consejo Comunitario establecieron acuerdos con los mineros delimitando las zonas de explotación y estableciendo zonas restringidas para la misma como el río Agualimpia, un afluente del Quinamayó, así como exigiendo un porcentaje por cada lavada de oro que sacaran los entables en razón del impacto ambiental y social generado. Sin embargo, los acuerdos poco fueron respetados a mediados del 2013 las retroexcavadoras fueron dirigidas a las orillas del río Agualimpia, lo que motivó a un grupo de mujeres a que con sus propios cuerpos fueran a impedir el paso de la maquinaría. 
A finales del año 2013 e inicios del 2014, autoridades tradicionales y organizaciones locales indígenas y afrocolombianas iniciaron acciones de hecho para expulsar las retroexcavadoras de sus territorios. Para ello fueron convocadas asambleas interétnicas para generar acciones de protección ante la expansión de la minería, a partir de las cuales se constituyó la Mesa Interétnica e Intercultural Permanente.

En síntesis, el contexto de conflicto en el que se desarrolla la acción del Consejo Comunitario Zanjón de Garrapatero no involucra directamente a actores armados en condición de disputa territorial sino a otros actores y procesos que hacen parte de una política estatal de retoma del control estatal y de recuperación económica de una zona influenciada por el conflicto armado.

Uno de las maneras en que la comunidad ha logrado mantenerse unida ha sido a partir de la producción de una narrativa entorno a la etnicidad como comunidad afrocolombiana y como Consejo Comunitario. Desde allí sea concretando un proyecto cultural y político orientado a la consolidación de una autoridad tradicional propia, que propende por los siguientes aspectos: a) la defensa de la autonomía territorial que exige sea consultada como instancia decisoria frente a cualquier proyecto o actividad a desarrollar en el territorio, b) el reconocimiento legal del territorio ancestral como territorio colectivo y c) el reconocimiento de un modelo de desarrollo propio. Estas tres dimensiones pueden evidenciarse en la respuesta del representante legal del Consejo Comunitario sobre el propósito de éste último:

\footnotetext{
“[...Zanjón de Garrapatero...] -lo que queremos-, tiene que ser la máxima autoridad administrativa del territorio de la comunidad de la gente que está afiliada a él, eso es un tema que es una consigna. Y autoridad de lo educativo, de lo ambiental, cultural, político, sociales y debemos llegar a un proceso de unificación de criterios de conceptos y de acciones, entonces eso es como un motor. ¿Qué tipo de autoridad o cómo sería esa autoridad? Hay que hablar de lo que dice la ley 70 que el concejo comunitario son máximas las autoridades étnicas desde la mirada afrocolombiana, pero también hay que mirar notoriedad, que sea hermana de las demás dinámicas o procesos. Que no porque seamos de la Etnia afro descendiente todos vamos a hacer a un lado, indígenas allá y los mestizos allá, si estamos en el proceso de reivindicación y reclamación de derechos nuestros, de nosotros como sujetos de especial protección, pero no que eso se quede solo en lo que dice la norma, sino llevarlo a la práctica y poder dar resultados" (Mina, 2013).
} 
Como se evidencia en la respuesta anterior, la narrativa del proceso organizativo se ha consolidado en un diálogo continuo con la Ley 70 de comunidades negras y las interpretaciones que de ella han hecho la Corte Constitucional con sus autos y sentencias, y otras organizaciones y comunidades afrocolombianas. Uno de los aspectos significativos en esta interacción ha sido la manera en que se ha significado la noción de territorio. Para Edier Loboa, el presidente del Consejo Comunitario, la reivindicación de las comunidades del norte de Cauca ha sido el reconocimiento de una territorialidad particular diferente a la de las comunidades del Pacífico.

"Nosotros tenemos unas dificultades, en esta zona del pais, en los valles inter-andinos es mucho más dificil la constitución de un concejo comunitario que la gente del pacifico, primero, porque hay una interpretación por parte de mucha gente sobre la ley 70, en donde se afirma que ésta es ese globo de tierra que ella describe en sus articulos. [...] Primero porque para el ministerio de interior y de justicia que es donde nos registramos nosotros como concejos comunitarios seamos de donde seamos, para poder ser reconocidos tienen que tener titulación colectiva, [...] pero para el caso de nosotros la posesión de la tierra es mucho más privada, lo cual hace que sea mucho más dificil que nuestros concejos comunitarios tengan titulación colectiva. No obstante, yo soy uno de los que reprocha ese concepto y apreciación del ministerio, porque no puede ser que para que le reconozcan a usted sus derechos como negro que habita este país, tenga que tener su comunidad un pedazo de tierra que diga que es de todos, cuando debiera dársele más importancia al concepto de territorio, el cual no es solamente la tierra, es todo lo que rodea la zona en donde estamos nosotros estamos asentados, es la cultura que nosotros conservamos, el medio ambiente, los ríos los cuales compartimos, la idiosincrasia de nuestras comunidades, todo el acervo cultural, todas nuestras riquezas son territorio. No puede ser que el Ministerio de Interior crea que tiene más significado un pedazo de tierra titulado a nombre de todos, que un territorio que puede ser incluso más grande que el pedazo de tierra y cuyo significado así mismo es mucho más grande." (Loboa, 2013)

Que esta narrativa esté orientada hacia los discursos legales de la Corte Constitucional o de la Ley 70 está relacionado con dos aspectos. De un lado con una tendencia no tan reciente, de que los líderes territoriales se formen profesionalmente como abogados. Este es el caso de Zanjón de Garrapatero por ejemplo, donde su presidente y su representante legal, 
siendo ambos las cabezas del proceso, son estudiantes de derecho, e incluso de otras ONG como PCN o de los líderes de la $\mathrm{ACONC}^{3}$. De otro, por la incorporación que ha tenido la Ley 70 dentro del discurso político que circula entre las organizaciones de la sociedad civil, afrocolombianas y no afro, e incluso entre las agencias de cooperación internacional que generan recursos económicos para la formulación de proyectos productivos y de fortalecimiento político-organizativo. Para unos y otros, la Ley 70 no sólo es un recurso legal provechoso para el reconocimiento de derechos territoriales y étnicos para las comunidades negras del norte del Cauca y del país, sino que contiene una clara narración sobre la identidad de las comunidades negras al describir cómo es su relación con el territorio, con su cultura y con lo político, lo que permite un diálogo frecuente entre cómo se piensan las comunidades que están en un tránsito hacia su auto-reconocimiento político como consejo comunitario y lo que espera, dice e interpretan cada una de las instancias del Estado.

Esta incidencia del discurso jurídico que se extiende a los autos y sentencias de la Corte Constitucional como el Auto 005, ha incidido en que varias de las acciones tomadas contra la minería, por la titulación de la Hacienda San Rafael y la solución de otros conflictos, haya estado orientadas a corresponder con una serie de acciones de carácter legal y jurídico. ¿Cómo ha afectado esto la dinámica de la relación entre contexto de conflictividad y acción colectiva?

\section{Resultados: el análisis de la acción colectiva en el contexto de conflicto}

Retomando los planteamientos hasta aquí esbozados, la acción producida por el consejo comunitario se da en un contexto de múltiples conflictividades, varias de las cuales son consecuencias factibles de un conflicto armado prolongado en la subregión, no obstante la movilización no está dirigida precisamente contra los actores armados sino contra otros actores sociales en la dinámica de estas conflictividades. ¿Cómo incide esta condición en la relación planteada?

Un aspecto significativo en el análisis en la interacción entre acción colectiva y contexto de conflicto armado está relacionada con las condiciones y el momento en el que está se produce. Por ejemplo el conflicto de la Hacienda San Rafael dio paso a que la comunidad

3 PCN, Proceso de Comunidades Negras. ACONC, Asociación de Consejos Comunitarios del Norte del Cauca. 
hiciera un tránsito hacia su constitución como consejo comunitario y a su asimilación como comunidad afrocolombiana. La acción se orientó hacia el Estado en su calidad y garante de los derechos étnico-territoriales de ambas comunidades. Si bien la situación generaba una amenaza a la cohesión interna de la comunidad y a sus relaciones territoriales, que se vieron notablemente modificadas con la instalación de la comunidad indígena, se constituyó en sí en una oportunidad política para la visibilización y reconocimiento organizativo del consejo comunitario. A diferencia de las acciones generadas contra la minería no legal.

Retomando la descripción con la que se da inicio a este artículo sobre las amenazas contra los diez líderes nortecaucanos por su movilización hacia la expulsión de la minería no legal de su territorio, puede decirse que allí se evidencia un cambio sustancial en las condiciones en las que se ha producido la acción colectiva hacia este conflicto. La acción estuvo dirigida en un primer momento hacia la generación de unos acuerdos con los dueños de los entables mineros para delimitar su expansión, y en segundo lugar con los miembros de la misma comunidad para evitar que continuara el arrendamiento de más predios para su explotación de oro, producto del apoyo que parte de la comunidad manifestó hacia la minería, dado que se veían beneficiados con la práctica del barequeo. En un primero momento la acción no estuvo dirigida hacia las instancias legales encargadas de la judicialización de la minería no legal en el municipio. Una vez los mineros incumplieron los acuerdos expandiéndose hacia zonas que habían sido decretadas como prohibidas por la comunidad, varias miembros de esta última comenzaron a movilizarse para evitar el paso de las maquinarias hacia otros predios que ponían en peligro la última fuente de agua cercana no contaminada por la minería. Es decir se dio paso a las "acciones de hecho". Simultáneamente a estas acciones comenzaron a organizarse las asambleas interétnicas con los resguardos vecinos afectados por la minería, y las audiencias mineras. En respuesta a estas acciones los mineros comenzaron a fortalecer su seguridad privada y finalmente el 29 de septiembre emitieron un comunicado amenazando de muerte a los líderes más visibles de la comunidad y aumentando el riesgo de la producción de la movilización comunitaria por esta causa.

Las condiciones que han contribuido a que esta la movilización contra la minería sea una acción colectiva de riesgo (Restrepo, García, y Bautista, 2010) ha sido la dinámica económica impulsada por la extracción ilegal de oro. Anclada a esta práctica se ha identificado actividades de lavado de activos y de financiación de grupos armados ilegales. De igual ma- 
nera el aumento del precio del oro incentivado por la crisis económica estadounidense del año 2012, ha contribuido al auge de esta actividad ilegal. Además de estos aspectos, se encuentra la asimetría que supone una interlocución con actores ilegales en la cual los últimos están en la capacidad de imponer decisiones y condiciones por encima de los acuerdos que van en contravía a sus propios intereses. De esta manera "la "acción de hecho" de Zanjón Garrapatero se ha ido acompañando de acciones "de derecho" que han buscado involucrar al Estado como garante de los derechos étnico-territoriales de estas poblaciones.

De otro lado, el sistema de oportunidades políticas, en este caso, se ha ido restringiendo en la medida en que la acción que se ha producido ha buscado ser más englobante frente a la problemática de la minería incluyendo en su definición de minería ilegal toda aquella minería que no ha sido consultada previamente de manera libre e informada con la comunidad, lo que incluye la minería transnacional. Dado que en el consejo comunitario hay un título minero otorgado por el Estado a la minera canadiense Anglo Gold Ashanti, las exigencias del primer actor frente al segundo incluyen reversar el título. En la media en que la movilización contra la minería ha buscado incidir en la política de desarrollo del gobierno nacional frente al territorio del norte del Cauca como una zona de desarrollo minero, las oportunidades políticas dentro del sistema político comienzan a verse más restringidas. En tal sentido, como lo advierten Restrepo, García y Bautista, esta condición es una causal de la acción colectiva sea riesgosa (Restrepo, García, y Bautista, 2010).

Con el estudio de estas dos situaciones del caso de estudio, puede decirse que la incidencia del conflicto armado en la producción de acción colectiva se ha dado en dos niveles: de un lado incentivando el tránsito en la manera en que se organiza la comunidad, entre una autoridad territorial interétnica y campesina hacia una autoridad territorial étnica. De otro, orientando la narrativa en torno a la cual se construye lo común y se identifica el tipo de acción colectiva que comienza a producir: en este caso la etnicidad como horizonte de significado se ha convertido en un recurso para orientar un proyecto cultural y político, la consolidación de una autoridad propia autónoma, en un contexto en donde se superponen una condición de continuación de la guerra y los procesos sociales producidos por esta misma.

Respecto al primer aspecto, la organización de la comunidad como autoridad étnica ha orientado el propósito de las reivindicaciones por la Hacienda San Rafael y la minería, hacia 
su reconocimiento legal ante el Ministerio del Interior. En el primer caso a partir de la titulación de la Hacienda como territorio colectivo, en el segundo, a partir del reconocimiento del derecho a la consulta previa, libre e informada.

La movilización de Zanjón de Garrapatero ha tenido tres propósitos de acción identificados por sus propios líderes son de tres tipos:

\section{Negociación}

La negociación y el diálogo son las primeras estrategias que ha planteado el consejo comunitario frente a los conflictos mencionados y ha tenido el propósito de evitar la agudización de los conflictos que afronta la comunidad como de los mismos conflictos internos que tienen lugar allí.

Frente al diálogo con las comunidades indígenas sobre San Rafael, funcionó en la medida en que ambas comunidades identificaron en el Estado el responsable del conflicto. Para ello se definieron comisiones de resolución de conflictos de la cual participan representantes de las comunidades y una comisión de diálogo conformada por el presidente de la junta y el gobernador del resguardo de Toribío. Como lo menciona Cristian Gros para el caso indígena, si el territorio es el aspecto más significativo, el elemento articulador de la historia de vida de la comunidad, ha sido el acceso restringido al mismo, lo que ha significado el origen de la desigualdad y la marginalidad de las comunidades indígenas, siendo éste uno de los aspectos que debe garantizarse para que la comunidad indígena perviva (Gros, 2010).

No obstante, el diálogo con los mineros no ha sido tan fructífero. El distanciamiento entre la narrativa propia del consejo comunitario en la que se defiende el territorio como lugar de vida y de desarrollo social y cultural propio de esta comunidad, frente a la narrativa del desarrollo en la que se paran los empresarios mineros no legales y las empresas transnacionales, ha obstaculizado la credibilidad, la construcción de consensos y el respeto mismo por estos escenarios de diálogo. Así lo describe el presidente del Consejo comunitario:

"Con la Ilegal, ha sido muy complicado porque con ésta uno no se enfrenta a una persona o a un grupo de personas que tienen claro el tema del territorio, la defensa del mismo, la importancia del medio ambiente, la protección de las comunidades, los bienes públicos de las comunidades, el respeto a los bienes públicos de 
esas comunidades, porque bienes públicos son los ríos, sus quebradas, todas esas cosas a las que todos tenemos derecho de hacer uso sin que nos cobren absolutamente nada, entonces para ellos ese concepto es atrasado. [...] Esa gente piensa como piensa el gobierno, con la gente asi, hablar de estos temas, bajo esa filosofia es muy complicado, porque para ellos lo único que hay en la cabeza es el signo de pesos, no importe lo que haya que hacer y cómo se consiga". (Loboa, 2013)

\section{Fortalecimiento de redes}

La construcción de alianzas y el fortalecimiento de los apoyos de organizaciones y comunidades de la sociedad civil ha sido una de las estrategias que fue efectiva para la visibilización a nivel nacional de los conflictos del consejo comunitario. Las alianzas se orientan tanto al interior del consejo comunitario como entre este y otros consejos y comunidades vecinas. Estas alianzas han sido definidas como estrategias para mantener la seguridad y proteger a los líderes de alguna represalia por ser las cabezas en las movilizaciones. De esta manera uno de los ejes de trabajo ha estado orientado hacia la formación política de los miembros al interior de la comunidad para mantener la cohesión interna y facilitar la solidez y la legitimidad de las decisiones del consejo comunitario.

\section{Acciones de hecho como acciones de presión}

El recurso de estas acciones se ha mantenido presente a lo largo de todo el proceso organizativo. En esta categoría se ubican la huelga de hambre organizada en el 2010 por habitantes de Mazamorrero para presionar al gobierno nacional frente a San Rafael. También el bloqueo de carreteras para impedir el paso de las retroexcavadoras. E incluso la toma de la sede del Incoder en Popayán como estrategia para presionar el avance de la política de tierras para las comunidades negras del Cauca.

De esta manera, la narrativa del proceso y su incidencia en la configuración de un tipo especial de acción colectiva, no sólo ha sido reactiva frente a los conflictos, sino propositiva y transformadora frente a los mismos. La constitución de una autoridad étnica propia como propuesta política y cultural ha implicado que el proceso construya y consolide definiciones y acciones en torno a cómo se entiende el territorio colectivo, la autonomía, el gobierno propio y el desarrollo propio. Este proceso de etnización supone en un proceso de diferenciación, es decir, de construcción de una frontera étnica o un "límite étnico", como lo menciona Frederik Barth. 
Este límite étnico comprende tanto "criterios y señales de identificación" como "estructuras de interacción" con otras comunidades, a partir de allí se canaliza la vida social y se organiza las relaciones sociales y de conducta de cada grupo étnico (Barth, 1976).

Parte de las estructuras narrativas de la interacción con otros actores como se ha evidenciado, ha sido de un lado el reconocimiento de una ancestralidad territorial con la cual se busca legitimar la presencia histórica de las comunidades negras en la zona plan del norte del Cauca, y de otro, el reconocimiento de una lógica territorial propia que permite una autoridad, una administración y una toma de decisiones de manera colectiva. Esta consolidación de lo que considero una frontera étnica ha sido la narrativa central de la acción contestaria en el tema de la minería y de San Rafael. Esta narrativa, no obstante, como fue mencionado más atrás, entra en conflictividad con los intereses del Estado, de minero, empresas transnacionales y grupos armados ilegales, lo que ha llevado a que la movilización en el último año se haya orientado a la consolidación de alianzas y procesos interétnicos locales. La asamblea interétnica contra la minería ha sido prueba de ello.

Retomando entonces los argumentos expuestos hasta el momento, considero importante subrayar que en la interacción entre conflicto armado y acción colectiva el primero no siempre se convierte en un factor generador de riesgo. Los conflictos pueden generar riesgo u oportunidad en la acción dependiendo de otros factores como son el contexto histórico de la confrontación armada, la trayectoria histórica y la trayectoria de movilizaciones de las comunidades involucradas, los recursos culturales y políticos que poseen estas últimas. No obstante un contexto de conflicto armado sí puede agudizar la restricción del sistema de oportunidades políticas para una comunidad, como sucede con la minería ilegal.

Para el caso de estudio, la estrategia más clara para hacerle frente al riesgo, ha sido la movilización de la solidaridad hacia la sociedad civil local, esto significa hacia organizaciones no gubernamentales, comunidades, academia, líderes y funcionarios públicos. Para el caso de estudio, el contexto de conflicto armado y los procesos sociales derivados del mismo, han posicionado al consejo comunitario Zanjón de Garrapatero ante el Estado como ante actores sociales locales, lo que ha contribuido de alguna manera a que el riesgo se incremente. 
De otro lado, el conflicto desde su definición sociológica como dinámica de cambio social, sumado a las condiciones de amenaza y oportunidad que han generado las conflictividades vividas por la comunidad ha incentivado su movilización y el fortalecimiento mismo del Consejo Comunitario como proceso y como autoridad étnica. Frente a ello señala Alexis Mina:

\begin{abstract}
"[el conflicto] Genera división y lesión en el tejido organizativo, pero se necesita ser dinámico, y gran parte de las acciones en el mundo se dan porque estamos en riesgo, en conflicto, es por medio de estas circunstancias que buscamos acciones y solucionarlo. Yo creo que ha ayudado más a legitimar el tema del concejo porque nos ha hecho movernos más, reunirnos más, nos ha hecho hablar más con la gente, la gente en el sentido de pertenecía al territorio, a la etnia, de todos estos elementos que nos hemos. Utilizado dentro de los discursos y procesos. Es malo que pasen conflictos, pero al tejido organizativo le ha ayudado para legitimarse y para moverse." (Mina, 2013).
\end{abstract}

Esta cita evidencia uno de los aspectos significativos de la narrativa del proceso organizativo en torno a lo étnico no sólo ha sido la capacidad unificación y consolidación de lo común en torno a una identidad colectiva, sino la capacidad de dialogar con otros actores y de articular nuevas narrativas para incidir en la política púbica, así como la capacidad de recuperación (Polletta, 1998). La narrativa étnica como significado de origen de una comunidad, permite enlazar y dar una lectura de la experiencia individual como experiencia comunitaria con un tipo de enlazamiento de consanguinidad simbólica. Los conflictos de Zanjón y las amenazas contra sus líderes, se ha convertido en un asunto de la comunidad local y de las comunidades negras del norte del Cauca. Por esta razón respuesta ha estado orientada en torno al fortalecimiento de esta capacidad colectiva de sentirse como una familia. De allí que tenga sentido la comprensión que alguno de sus líderes hace sobre lo comunitario y la colectividad étnica como una familia: "porque nosotros, la familia afro lo que le duele a uno, le duele al otro" (Mina, 2013). 


\section{Conclusiones}

El estudio de caso permite formular las siguientes inferencias analíticas que podrían servir para la comprensión de otros casos. Primero, el estudio de caso de Zanjón de Garrapatero permite entenderlo en un contexto de reconfiguración de múltiples conflictividades territoriales que son el producto de las transformaciones de las redes y dinámicas sociales, políticas y económicas locales que ha producido una guerra prolongada en la subregión. Estas incluyen las acciones de recuperación del monopolio de la fuerza de parte del Estado colombiano a través del aumento del pie de fuerza y de proyectos de inversión extranjera en ciertas regiones, como de la agudización de las acciones bélicas de los actores armados ilegales -ahora mucho más diversos y con difusas distinciones políticas-, y con el fortalecimiento de procesos de autonomía territorial de comunidades rurales.

Segundo, la manera en que la comunidad ha interpretado al menos dos de los conflictos que ha afrontado, el de San Rafael y el de la minería no legal, como amenaza u oportunidad permite producir un tipo de organización y de acción colectiva específica. Un contexto de conflictividad interétnica como el de San Rafael, entendido en términos de amenaza y oportunidad, se convirtió en oportunidad política para que la comunidad reorientara su proceso organizativo en torno a lo étnico y desde allí se encaminara en un proceso de reivindicación de derechos por la tierra y por su derecho de habitar y vivir en ella. Un conflicto como el de minería, entendido en condición de amenaza y riesgo, ha generado acciones más cautelosas en las que el consejo comunitario ha buscado minimizar el riesgo de la acción generando alianzas con otros actores y fortaleciendo un frente común popular frente a la minería. Frente a ello también se han producido acciones de derecho orientadas hacia la procuraduría, defensoría y contraloría nacionales y locales.

Tercero, la consolidación colectiva de la identidad étnica afro en este caso se convierte en un horizonte de significado para consolidar lo común y definir fronteras de diferencia con otras comunidades. Tiene un propósito claro también de alcanzar cierto marco de oportunidades políticas dispuestas en el campo de lo legal para posibilitar la permanencia de una comunidad en un territorio, y esto no es sólo su supervivencia física como individuos, sino su supervivencia social como comunidad y su supervivencia cultural. No obstante, para el caso de estudio si bien el marco legal es una oportunidad política que 
implica un punto de partida, el estado de no legalidad del consejo comunitario convierte su reconocimiento legal en un propósito final de la acción colectiva desarrollada, y en una nueva estrategia de defensa ante la llegada de la transnacional minera.

Cuarto, la acción colectiva de Zanjón de Garrapatero ha tenido un propósito de efectividad durante estos años y ha sido particularmente la consecución del apoyo y la solidaridad de la sociedad civil: de organizaciones étnicas, de comunidades de otras veredas, de ongs de universidades e incluso de otros movimientos sociales. Junto con ton ellas ha buscado el fortalecimiento y la definición de mecanismos democráticos para asegurar interlocución válida, para a través de ellos exigir al Estado el reconocimiento de sus derechos étnico-territoriales y tener elementos legales para defenderse activando redes transnacionales al gigante transnacional que amenaza con la fractura social, cultural, económica e incluso geográfica de Zanjón de Garrapatero y de los otros consejos comunitarios y resguardos vecinos.

Quinto, el papel de la identidad étnica en estos contextos de conflicto ha sido el de proveer una narrativa de la recomposición comunitaria, de conectar las experiencias y proyectos individuales en torno a las experiencias y proyectos comunes. Para Gros, la identificación comunitaria en el nivel narrativo de la etnicidad "funciona como un espacio de protección”, incluso, sugiere el autor citando a Polanyi (1983), cuando la política de neoliberalización amenaza a la persona y a su grupo (Gros, 2010: 65-66). Sea entonces esta reflexión un llamado a incorporar la comprensión de las tramas culturales en el análisis político.

\section{Bibliografía}

Asamblea interétnica Resguardo Guadualito y CC Zanjón de Garrapatero. (septiembre de 2014). Comunicado de la Asamblea Interétnica del Resguardo Indígena Guadualito y el Consejo Comunitario de Zanjón de Garrapatero. Obtenido de biodiversidadla: http://goo.gl/c7FR17

ERAZO GÓMEZ, A. (2012). "La Ley 70 de 1993 y la participación política de las comunidades negras”. En: Trans-pasando Fronteras, núm. 2, pp. 31-45. Cali, Universidad Icesi.

BARTH, F. (1976). "Introducción”. En F. Barth, Los grupos étnicos y sus fronteras. 
La organización social de las diferencias culturales (págs. 9-49). Ciudad de México: Fondo de Cultura Económica.

COHEN, J. (1995). Estrategia e identidad. Nuevos paradigmas teóricos y movimientos socials contemporáneos. (6), 15-69.

CONSOLIDACIÓN. (s.f.). Consolidación. Recuperado el 2014 de mayo de 20, de http://www.consolidacion.gov.co

GOLDSTONE, J., y Tilly, C. (2001). “Threat (and opportunity): popular action and State response in the dynamics of contentious action". En R. Aminzade, y y. otros, Silence and Voice in the Study of Contentious Politics (págs. 89-195). Nueva York: Cambridge University.

GROS, C. (2010). Nación, identidad y violencia. Bogotá: IEPRI, Universidad Nacional de Colombia, Universidad de los Andes.

ISACSON, A. (2012). Consolidating “Consolidation” Colombia's "security and development" zones await a civilian handoff, while Washington backs away from the concept. Washington: Washington Office on Latin America (WOLA).

MELUCCI, A. (1994). “Asumir un compromiso: identidad y movilización en los movimientos sociales". En: Zona Abierta, 153-179.

MELUCCI, A. (2002). Acción colectiva, vida cotidiana y democracia. Ciudad de México: El Colegio de México, Centro de Estudios Sociológicos.

POLlETA, F., y Chen, P. C. (2012). Narrative and Social Movements. The Oxford Handbook of Cultural Sociology.

POLlETTA, F. (1998). “Contending Stories: Narrative in Social”. Qualitative Sociology, 21(4), 419-441.

RESTREPO, G. I., García, P., y Bautista, S. y. (2010). ¿Un índice de riesgo de las acciones colectivas emprendidas en las zonas rurales? En: Contra viento y marea. Acciones colectivas de alto riesgo en zonas rurales colombianas 1985-2005. Bogotá: La Carreta Editores, IEPRI. 
TARROW, S. (1997). "Explotación y creación de oportunidades". En T. Sydney, El poder en movimiento. Los movimientos sociales, la acción colectiva y a política (T. p. Resines, Trad., pp. 147-178). Madrid: Alianza Editorial.

\section{Entrevistas}

CAPAZ, E. (2012). Situación de DDHH en el norte del Cacua. (M. J. López, Entrevistador).

LOBOA, E. (octubre de 2013). Perpepciones e historia del proceso organizativo. (M. J. López, Entrevistador).

MINA, A. (octubre de 2013). Perspeciones sobre proceso organizativo. (M. J. López, Entrevistador). 